\title{
PODER DEMÓTICO AO POVO: O TRIUNFO DO DIMOTIKI, O TRIUNFO DE MEDEIA
}

\author{
ANASTASIA BAKOGIANNI*
}

The Open University, UK

\begin{abstract}
Resumo. Este texto analisa uma produção moderna da Medeia de Eurípides (431 a.C.) nos últimos anos do século passado. A releitura da tragédia antiga, que é objeto desta minha discussão, foi apresentada no Teatro Nacional da Grécia, em 1997, e dirigida por Niketi Kontouri. Representativa de um ambiente específico que, acredito, foi promovido no estado moderno grego depois da resolução oficial relativa à infame "Questão da Língua", essa montagem também oferece uma perspectiva singular a partir da qual se pode reexaminar a Medeia de Eurípides e a recepção do drama grego no mundo moderno.
\end{abstract} Palavras-Chave. Medeia; Eurípides; recepção. D.O.I. 10.11606/issn.2358-3150.v18i2p159-179

Este texto analisa uma produção moderna da Medeia de Eurípides (431 a.C.) nos últimos anos do século passado. Esse drama sobre a heroína homônima que comete infanticídio cativou o público do século xx (Iles Johnston 1997, 4) e continua a estimular o debate e a atrair novas recepções atualmente. ${ }^{1}$ A releitura da tragédia antiga, que é objeto desta minha discussão, foi apresentada no Teatro Nacional da Grécia, em 1997, e dirigida por Niketi Kontouri. ${ }^{2}$ Escolhi explorar essa produção em particular, porque ela é representativa de um ambiente específico que, acredito, foi promovido no estado moderno grego depois da resolução oficial relativa à infame

- PhD in Classics at Royal Holloway College, University of London (2004).

** Artigo recebido em 25.set.2015 e aceito para publicação em 14.dez.2015. Tradução de Maria Cecília de Miranda Nogueira Coelho.

${ }^{1}$ A recepção desta heroína trágica tão singular se tornou um importante estudo de caso; Ver: Clauss and Iles Johnston (1997), Corti (1998), Rubino (2000), Hall, Macintosh and Taplin (2000) e Bartel and Simon (2010). Sobre a relevância do drama euripidiano em geral para o mundo moderno, ver Walton $(2009,2-3)$.

${ }^{2}$ Medeia tem recebido muitas e ilustres apresentações no Teatro Nacional. Antes da produção de 1997, ela foi reapresentada em 1942, em 1956 (dirigida por Alexis Minotis e estrelando Katina Paxinou), em 1957 (id.), em 1958 (id.), em 1968-1971, em 1973-1974, em 1976-1978, em 1993 e mais recentemente em 2003 (fonte: Archive of the National Theatre of Greece: <http://www. nt-archive.gr>, acesso em 14.02.2011). Montouri também dirigiu Antígona para o Teatro Nacional em 2002, assim como outras peças modernas. 
"Questão da Língua". ${ }^{3} \mathrm{O}$ aceite gradual dessa resolução conduziu a uma nova era na apresentação do drama antigo no palco grego moderno - algo que pode ser defendido como mais "democrático" em termos do lógos e em termos de sua abertura e permeabilidade por diferentes modelos teatrais. ${ }^{4}$ A releitura grega moderna de 1997 também oferece uma perspectiva singular a partir da qual se pode reexaminar a Medeia de Eurípides e a recepção do drama grego no mundo moderno. ${ }^{5}$

O ponto inicial de minha análise será o exame dos contextos que orientam esta recriação grega moderna de 1997. Eles modelaram a forma e o estilo que a produção escolheu adotar. Vários elementos na concepção geral da produção orientam a sua compreensão e o seu posicionamento histórico, ideológico e cultural. Limitações de espaço naturalmente reduzem a amplitude dessa discussão, mas espero desvencilhar alguns elementos que influenciaram a concepção geral da produção.

\section{CONTEXTO: UMA RELEITURA GREGA MODERNA}

A produção de 1997 não pode ser divorciada do seu contexto grego moderno. A crença na existência de uma "relação especial" entre o passado clássico e o Estado moderno forma um elemento crucial e algumas vezes discutível no modo como os gregos modernos construiriam sua identidade nacional. No teatro, isso se traduziu no desejo de reapresentar a tragédia grega antiga, com o resultado de ela mesma se tornar um campo de batalha. Esse desejo se manifestou ao longo do século xix e continua a se fazer presente ainda hoje.

É significativo que a produção de Medeia que estamos discutindo tenha sido montada pelo Teatro Nacional da Grécia, a primeira companhia do país. Ela foi fundada em 1930 e se tornou rapidamente representativa de tendência teatral dominante e uma bússola dando a direção para o teatro moderno em geral. ${ }^{6}$ Tal grupo de teatro usufrui, assim, do capital cultural

\footnotetext{
${ }^{3}$ Para uma discussão da "Questão da Língua Grega", ver: Beaton (1999), Georgakopoulou and Silk (2009) e Mackridge (2010).

${ }^{4}$ Para uma discussão sobre esse termo, e o debate sobre a "virada democrática", ver: Hardwick and Stray $(2008,3)$ e a introdução do volume, no qual a versão inglesa desse texto foi publicada: Classics in the Modern World: A "Democratic Turn"?, ed. L. Hardwick and S. J. Harrison, Classical Presences, Oxford University Press, 2013.

${ }^{5}$ Para os estudos de caso que demonstram a importância do exemplo grego moderno dentro de um contexto mais amplo do drama grego na Europa, ver: Symvoulidou (1998) e Eliade (1999).

${ }^{6}$ Para a história do National Theatre of Greece e sua missão e princípios, ver: <http://www.n-t. gr/en/nationaltheatre/>, acesso em: 15.02.2010.
} 
(Van Steen 2010, 22-3), bem como do suporte financeiro para assegurar que suas produções alcancem ampla audiência, tanto no país como no exterior.

No século xx, apresentações em espaços abertos tornaram-se um aspecto importante do diálogo entre o teatro grego antigo e o moderno (Michelakis 2001, 241-6). ${ }^{7}$ Acredita-se que o espaço físico dos primeiros acrescenta uma dimensão extra para a encenação de tais recriações, porque as peças teatrais antigas estão novamente sendo apresentadas em espaços onde o drama teria sido encenado na Antiguidade, trazendo, assim, o passado para mais perto do presente. O teatro antigo em Epidauro é, provavelmente, o mais famoso espaço teatral ao ar livre na Grécia moderna, e a produção de 1997 de Medeia foi apresentada ali no início de sua temporada (at the beginning of its run). ${ }^{8}$ A produção foi também apresentada em outros teatros antigos, inclusive no Odeon de Herodes, em Atenas. ${ }^{9}$

Um aspecto crucial do contexto grego moderno é a "Questão da Língua Grega", isto é, a escolha entre katharevousa e demótico. Katharevousa foi uma língua construída artificialmente, purgada de elementos estrangeiros, com a finalidade de torná-la mais próxima do grego antigo. Era a língua oficial, ensinada nas escolas e universidades. Demótico era a língua de fato falada pela maioria da população no dia a dia. Esse fenômeno de diglossia, a existência de duas línguas nacionais competindo, dificultou a prática de ambas, do logos escrito e falado da Grécia moderna por quase um século (1888-1976)..$^{10}$ O Glossiko Zetema, para usar o termo grego moderno, foi notório em incidentes como os do Evangelika (1901) e do Oresteiaka (1903), e suas controvérsias em torno de traduções do Evangelho e da Orestéia, respectivametne. ${ }^{11}$ A questão em jogo, naqueles dias, era se seria apropriado traduzir em um idioma mais popular a Bíblia e a trilogia de Ésquilo, que era considerada equivalente à primeira em termos de capital cultural. Seto-

Sobre o importante papel que o teatro antigo tinha na recriação do drama grego no Estado moderno, ver também Mauromoustakos (1999, 84-5).

${ }^{8}$ O festival de verão de Epidauro começou em 1954 com a encenação do Hipólito, de Eurípides. Georgousopoulos and Savas (2002, 103-14). Ele continua até o presente, sob a égide de Hellenic Festival: <http://www.greekfestival.gr/gen_content.aspx?pgid=0>, acesso em: 15.02.2011). A produção de 1997 recebeu sua première em outro teatro antigo, o de Dodona, em 16.07.1997. Ela foi, então, para o antigo teatro de Dio (26.07.1997) antes de ir para Epidauro em 01.08.1997-02.08.1997.

${ }^{9}$ A versão da produção que foi gravada para o arquivo do National Theatre of Greece foi filmada nesse teatro antigo.

${ }^{10}$ Para o fenômeno da diglossia, ver: Alexiou 1982 e Fragoudaki 1992. Para uma análise dos 100 anos de luta sobre a questão da língua do Estado moderno grego, ver Fragoudaki 2001.

${ }^{11}$ Para mais informações sobre Evangelika e sobre o papel que eles tiveram na questão da lingual grega, ver Carabott 1993. Para o episódio da Oresteiaka, ver: Van Steen (2008, 360-72) e Spathes (2005). No último, ver, em particular, o capítulo "The stage director and the production of the Oresteia at the Royal Theatre" (229-66). 
res conservadores viram nessa tentativa uma corrupção do verdadeiro logos desses textos e lutaram incisivamente contra isso. Sob a pressão desses puristas da linguagem, foi introduzida a cláusula 107 na Constituição de 1911, proibindo quaisquer mudanças nos textos. ${ }^{12}$ Os puristas acreditavam que qualquer tentativa de diluir a katharevousa seria um ataque à nação mesma. George Mistriotis (1840-1916), um professor da Universidade de Atenas e um dos líderes no movimento dos puristas, caracteristicamente afirmou que "demoticistas não eram gregos".13 O Glossiko Zetema estava, assim, intrincadamente ligado à questão da identidade nacional e da autenticidade.

A escolha de uma linguagem moderna para a recriação de um drama antigo teve, então, implicações ideológicas significativas. Na visão dos puristas, a decisão de usar o demótico como linguagem para a apresentação, a fim de promover a recriação do drama grego antigo no palco grego moderno, implicou, automaticamente, a falta de autenticidade, uma negação da essência de ser grego. Ao longo da segunda metade do século xix, apresentações gregas modernas de releituras de tragédias gregas antigas eram produções "racionais", direcionadas por uma abordagem filológica. Essas apresentações eram meras ilustrações de textos gregos antigos e falhavam no apelo ao público. No início do século xx, mudanças importantes ocorreram, e as produções começaram a ganhar um caráter mais performativo, utilizando de modo mais amplo os recursos que o palco do teatro grego moderno oferecia aos diretores. Do mesmo modo, os atores pararam de declamar seus papéis vestidos com figurinos de época (arqueologicamente precisos), e passaram a "atuar" mais nas peças. O resultado foi que essas representações se tornarem mais atraentes para o público em geral.

Esses desenvolvimentos ocorreram apenas gradualmente no período de muitas décadas. Konstantinos Christomanos, da Nea Skene Company, e Thomas Oikonomou, do Royal Theatre, estavam entre os primeiros de uma nova geração de diretores profissionais de teatro que experimentaram a tradução de dramas antigos em um registro mais vernacular da língua grega. ${ }^{14}$ Essa evolução de uma katharevousa mais opressora para um demótico popular aconteceu paralelamente a um crescimento de popularidade do drama

${ }^{12}$ George Mistriotis em um discurso apresentado na University of Athens, no período da redação da nova constituição intituladada dimotiki "uma amputação e uma violação" da língua grega (Mistriotis 1911). Para uma perpectiva crítica, ver Fragoudaki 1977. A cláusula 107 não foi repelida até 1975.

${ }^{13}$ Mistriotis 1911. A ênfase é minha. Ele foi um dos principais agitadores das manifestações da Oresteiaka (6-9 de novembro de 1903). E encorajou seus estudantes a protestar contra o uso de uma tradução menos "pura", de George Sotiriades, para a apresentação da trilogia de Ésquilo no Royal Theatre, que havia ocorrido uns dias antes.

${ }^{14}$ A recepção de Aristofánes fornece um estudo de caso interessante para esse fenômeno. (Van Steen 2000). 
grego antigo para o palco grego moderno. O processo de democratização da linguagem, que foi abraçado por autores modernos proeminentes, como, por exemplo, o poeta Kostis Palamas (1859-1943), ${ }^{15}$ alimentou uma releitura genuína da tragédia grega antiga e a emergência de espetáculos teatrais acessíveis e animados. Os festivais délficos de Angelos e Eva Sikelianos em 1927 e em 1930 representaram o drama esquiliano em traduções para o demótico e cultivaram todos os outros aspectos performativos das produções genuínas para grandes audiências como cenário, figurino, música, coreografia etc. ${ }^{16}$ No entanto, a ditadura de Metaxas (1936-1941), os turbulentos anos da segunda grande guerra (1941-1944) e a guerra civil que se seguiu (1946-1949) interromperam o desenvolvimento do teatro grego moderno. Na segunda metade do século, porém, houve um compromisso renovado para reviver as peças antigas, de modo que fossem atraentes para o público moderno. Essa abordagem determina, em particular, o trabalho de Karolos Koun..$^{17}$ Koun e os que seguiram seus passos favoreceram novas abordagens para a releitura da tragédia grega para o palco grego, e eles deliberadamente desafiaram a obsessão com a "autenticidade" dos conservadores (sobre o tema, veja, mais à frente, Gamel and Varakis).

Em 1976, o longo debate sobre a língua foi finalmente resolvido quando o demótico se tornou o idioma oficial da Grécia moderna por um ato do Parlamento (Mackridge 2010, 319). Após um período de ajustes, novos desafios foram colocados para a abordagem tradicional da encenação do drama antigo. ${ }^{18}$ Diretores queriam atrair e capturar a atenção do público moderno. Assim, eles esperavam ilustrar o impacto contínuo do drama antigo, apelando não para a autenticidade, mas criando um espetáculo acessível e envolvente. Defendo, aqui, que a produção da Medeia de 1997 é democrática/inclusiva, no sentido de exibir uma abordagem ousada para a recriação do drama grego antigo, tornada possível pela adoção oficial de uma língua que é mais acessível a todos os setores da audiência pretendida. A decisão de adotar a língua falada pelo "povo" alimentou um clima no qual abordagens mais inovadoras para as representações dessas peças antigas gradualmente tornaram-se mais aceitáveis e, de fato, mais encorajadoras.

\footnotetext{
${ }^{15}$ Para mais informações sobre Palamas e a vitória do dimotiki, ver Fletcher 1984.

${ }^{16}$ Para uma história da recriação do drama antigo entre os anos 1817 e 1932, ver Sideres (1976). Para o estado da dramaturgia moderna grega no século XIX e no início do XX, ver Chatzipadazis (2002). Minha discussão sobre o desenvolvimento da recriação do drama antigo no início do século xx no palco grego moderno foi significantemente auxiliada por uma série de conversas que tive com Gonda Van Steen, em 2009, durante uma visita aos EUA, patrocinada pelo British Council.

${ }^{17}$ Para Koun, ver Van Steen 2000, 124-89.

${ }^{18}$ Sobre as mudanças ideológicas depois da reforma de 1976, ver: Moschonas 2009, 293-320 e Goutsos 2009, 321-39.
} 
A produção de Medeia de 1997 foi, assim, caracterizada pelo desejo de desafiar a muito contestada necessidade de autenticidade, uma característica de muitas recriações de peças antigas no palco grego moderno. Produções anteriores específicas foram constrangidas pela necessidade de se retornar à produção original, "autêntica", e isso era visto como um passo no estabelecimento da conexão entre o antigo e o moderno no palco teatral. $\mathrm{O}$ uso da katharevousa como a língua de muitas dessas primeiras recriações era um elemento essencial na construção da autenticidade estética. Foi apenas após a adoção oficial do demótico, no entanto, que a "Questão da Língua" gradualmente parou de assombrar tanto no horizonte do teatro. Várias características da produção da Medeia de 1997 foram desenvolvidas para desafiar as abordagens mais tradicionais na encenação do drama antigo. A produção se aproximou de um conjunto de modelos e de práticas teatrais. Assim, deliberadamente, ela construiu um tipo diferente de relação com o público grego atual. ${ }^{19}$

\section{A CONEXÃO JAPONESA}

A linguagem da produção poderia fazer referências ao contexto grego moderno, mas, de outro modo, ela deliberadamente desafiou as convenções neoclássicas abraçadas pelos praticantes da recriação do drama grego, que eram firmemente enraizadas nos modelos do século XIX. ${ }^{20} \mathrm{~A}$ produção de 1997 escolheu, em vez disso, pegar emprestado criativamente um conjunto de elementos rituais derivados dos modelos e das práticas de teatro japonês e aplicá-los de uma forma modificada.

Kontouri estava seguindo os passos de Theodoros Terzopoulos, outro diretor grego contemporâneo, ao enfatizar os elementos japoneses em sua produção. Terzopoulos foi o diretor artístico do International Meetings for Ancient Drama at Delphi (1985-1988), para o qual ele convidou, dentre outros, o diretor japonês Tadashi Suzuki, que compartilhava o seu interesse na recriação do drama grego antigo e na exploração de novas abordagens

${ }^{19}$ A recepção da produção por um público internacional e a diáspora grega é atestada nos jornais, nos artigos de revista e nas resenhas que se encontram nos arquivos do National Theatre, em Athens.

${ }^{20}$ Os modelos ocidentais neoclássicos teatrais da Europa moldaram a dramaturgia moderna grega no período que vai até a Guerra de Independência de 1921. Na diáspora grega, em cidades como Odessa, apresentações teatrais com estórias e temas antigos eram bem populares. Essas peças tornaram-se a rallying cry para a revolução. Foi, no entanto, a recepção neoclássica dessas estórias que foram montadas, e não a própria recriação do drama grego antigo. Van Steen 2010, 125-46. Sobre a influência dos modelos europeus, veja também Grammatas, 2006, 113-14. 
teatrais na sua encenação. A conexão de Terzopoulos com a tradição teatral japonesa foi triunfalmente celebrada em 1999, quando ele organizou a segunda olimpíada do teatro, intitulada "criando esperança", em Shizuoka, no Japão. Terzopoulos desafiou a recriação do drama antigo com sua inovadora The Bacchae, em 1986. ${ }^{21}$ Ele escolheu focalizar a importância do corpo na apresentação, pegando emprestado práticas rituais de outras culturas, principalmente da tradição teatral japonesa. Terzopoulos teve um papel chave em moldar a recepção do drama antigo no palco grego moderno na segunda metade dos anos de 1980 e 1990. Sua afinidade com os modelos japoneses e o privilégio dado aos rituais primitivos e ao corpo na apresentação tornaram-se um modelo de imitação para os novos diretores que queriam se apartar das abordagens tradicionais para encenar o drama antigo no palco moderno. ${ }^{22}$ No caso de Medeia, no entanto, a recepção de sua história por Terzopoulos foi mediada pelo trabalho de Heiner Müller, com quem ele havia estudado no Berliner Ensemble (1972-1976). Ele encenou a Medeia Material, de Müller, em 1988, e novamente em 1996, um ano antes da produção de Kontouri, que escolheu, em vez disso, voltar ao texto fonte de Eurípides, embora ela tivesse também se inspirado no método de atuação de Terzopoulos e na sua afinidade com as práticas teatrais japonesas.

Em relação aos modelos do teatro japonês, a produção do National Theatre era influenciada pelo trabalho do diretor Yukio Ninagawa (1935-?), e, em particular, por sua produção de Medeia..$^{23}$ A retomada do drama grego por Ninagawa era modelada pelas tradições do teatro japonês. Curiosamente, foram precisamente aqueles elementos japoneses na recriação de Kountori que fizeram Ninagawa fazer objeções quando ele viu a produção que estava em turnê pelo Japão. Ninagawa gostou da atuação da atriz Karabeti no papel principal, mas não na direção. Ele ficou bastante irritado com o uso de bonecos para representar os filhos de Medeia, porque ele pensou que eles abalariam o impacto da história. ${ }^{24}$ Para um público grego moderno, entretanto, sem familiaridade com as tradições teatrais japonesas, esses elementos da produção permitiram uma distância crítica necessária para

\footnotetext{
${ }^{21}$ Terzopoulos fundou o Attis theatre company em Delfos, em 1985, e buscou explorar os modos como as tragédias gregas antigas poderiam ser apresentadas no palco moderno. Para seu trabalho com o Attis, ver: <http://www.attistheatre.com/el/I ITOPIKO/terzopoulos.html>, acesso em 22.01.2012. Sobre a recriação do drama antigo no repertório de sua companhia, ver: <http://

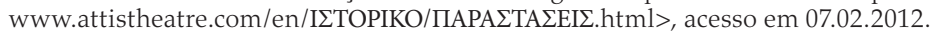

${ }^{22}$ Para uma exploração do método de Terzopoulos por outros diretores e acadêmicos, ver: Varopoulou 2001 e Raddatz 2006.

${ }^{23}$ Ninagawa encenou a Medeia de Eurípides várias vezes: em 1978, 1983, 1986, 1987, 1989, 1994, 1995, 1998 e 2005. Uma cópia da apresentação gravada em Tokyo em 31.10.1993 está na APGRD: <http://www.apgrd.ox.ac.uk/database>, acesso em: 01.06.2010.

${ }^{24}$ Asahi Shimbun (26.06.1999). Resenha acessível online (acesso em 20.03.2010).
} 
assistir a esse retrato da dissolução de um casamento no palco. ${ }^{25} \mathrm{O}$ comentário de Ninagawa, porém, criou o fantasma de transferir uma produção para fora das fronteiras de um país e de traduzir uma cultura, assim como palavras de uma peça (Hardwick 2000).

A adoção deliberada desses rituais, símbolos e práticas teatrais pouco familiares evitou que a peça caísse em um melodrama, ao produzir um distanciamento para o espectador. Todos os atores na produção estavam cobertos com pintura branca no corpo e a face era bastante maquiada. Esse aspecto da produção ecoou as práticas do kabuki, uma forma japonesa de dança dramática (Leiter 2002 e Kawatake 2003) ${ }^{26}$ Na produção de 1997, Medeia usou um vestido justo, vermelho escuro, e estava coberta com maquiagem branca, com os lábios pintados de vermelho e com uma faixa da mesma cor em um lado da face. A cor vermelha tem conotações especiais no kabuki (Kawatake 2003, 108-9). Ela é associada a papéis de aragoto, vilões do kabuki, cujas faces são decoradas com fitas vermelhas, sobre uma face branca, um estilo de maquiagem conhecido como kumadori. O uso desse estilo não é restrito aos papéis de aragoto, mas pode também ser aplicado a heróis e a poderes supernaturais que assumem a forma humana. O princípio que caracteriza tais papéis é aquele de transcender o dia a dia; todos eles são, cada um a sua maneira, "super-homens".

A escolha dessa cor para o figurino e para a maquiagem da atriz, fazendo o papel título na produção de 1997, criativamente jogou com o $k u$ madori para sugerir a intensidade da paixão e da vingança sobre-humana de Medeia. Ela é algo muito mais que um ser humano, como a sua fuga na carruagem-dragão durante o clímax da tragédia demonstra..$^{27}$ Em comparação, o branco é a cor que melhor descreve Lazaros Georgakopoulos, o ator que faz Jasão. Vestido de branco e coberto com pintura de igual cor, ele se empalidece, se comparado com a apaixonada e colorida Medeia. As primeiras duas vezes em que aparece no palco, ele usa um colar e uma armadura, mas no fim da peça já perdeu os dois. Eles são símbolos visuais importantes dos benefícios que ele espera ganhar com seu novo casamento com a princesa de Corinto. No fim, seu torso nu simboliza o estado no qual

\footnotetext{
${ }^{25}$ Walton argumenta que a exploração desconfortável do casamento por Eurípides em sua Medeia reverbera e desconforta o público moderno, assim como ocorreu com o público antigo $(2009,56)$.

${ }^{26}$ Sobre o uso da maquiagem no kabuki, ver Kawatake 2003, 109-12 (ill. 9-11).

${ }^{27}$ Mastronarde argumenta que Eurípides omite poderes especiais de Medeia e no final eles aparecem como surpresa $(2010,200)$. Os poderes de Medeia, no entanto, estão apenas adormecidos e a aparição da carruagem do Sol é uma lembrança de que ela é mais do que uma mulher mortal qualquer. Mesmo a recriação de 1997, que como um todo desconsidera os poderes da heroína trágica mantém o final original. Isso será discutido mais adiante.
} 
ele foi deixado por Medeia: ele se tornou alguém vulnerável, um homem ordinário que perdeu não apenas sua nova mulher, mas também os dois filhos do primeiro casamento.

Os figurinos usados pelos outros membros do elenco na produção de 1997, e a maquiagem aplicada em seus corpos e faces fornecem pistas sobre seus caráteres aos espectadores. Os dezoito membros do coro estão vestidos com roupas brancas. Eles usam bonés brancos, e seus corpos são cobertos com pintura branca. Foi colocada sombra azul nos olhos, e listras azuis completam sua caracterização. O esquema de cores frias é sugestivo de seu papel como mediadores entre Medeia e o resto do mundo. Eles têm simpatia por ela e temem seu temperamento apaixonado, mas nunca compartilham seus sentimentos, nem podem entender o seu desejo extremado de vingança. A mensageira que traz a novidade da horrível morte de Creonte e sua filha é particularmente impactante, com metade de seu corpo pintado em branco e a outra metade em marrom. ${ }^{28}$ A natureza dúbia de sua mensagem é visualmente indicada: más notícias que trazem alegria para Medeia. Creonte está vestido com um robe negro, com uma saia em dourado escuro, que é sugestiva de seu papel como perseguidor de Medeia. Em relação ao teatro grego moderno, essas eram escolhas de figurinos e maquiagem pouco usuais que ajudaram a distanciar a audiência da ação no palco e acrescentaram o sentido de "alteridade" que ela carrega.

O estilo na atuação da produção de 1997 também tem um débito criativo com o kabuki. Esta é uma forma de arte muito precisa na qual cada movimento conta (Llewellyn-Jones 2005, 76). O estilo de atuação dessa releitura evocou a graça da coreografia do kabuki. Nenhum ator ou atriz do Ocidente pode, naturalmente, duplicar os movimentos e gestos desse estilo de apresentação japonesa, cuja prática é um privilégio herdado de um grupo de famílias japonesas (Leiter 2002, xxII). Criativamente, a produção moderna grega adotou certos elementos para aumentar a sensação de que o que ocorre no palco é um espetáculo de tipo ritualizado. Kontouri, no entatno, subverteu a prática usual do kabuki, em que os papéis femininos são encenados por atores (onnagata). Talvez ela acreditasse que o público moderno grego, acostumado à estética ocidental realista, teria achado particularmente alienador não ter uma atriz no papel principal. Ironicamente, as demandas por autenticidade teriam levado ao uso de um ator para o papel de Medeia.

\footnotetext{
${ }^{28}$ Walton inclui este discurso da mensageira e o de Medeia a seus filhos (1019-80) na sua lista dos "grandes papéis" da tragédia grega (2009, 168-74). Ambos têm potencial para grande impacto dramático, quando manejados adequadamente no palco, como na recriação de 1997.
} 
O uso de grandes bonecos para representar os filhos de Medeia, em vez de atores crianças, se apoia na tradição teatral japonesa, qual seja, a do bunraku, ou teatro de bonecos (Hironaga 1976, 1-25). A manipulação adequada dos bonecos requer a simpatia do público, mas sua face neutra também universaliza tanto quando despersonaliza os filhos de Medeia. Esta foi uma escolha de Kontouri, porque os bonecos bunraku têm, de fato, faces que podem ser manipuladas. Os olhos, as sobrancelhas e a boca podem ser movidos (Hironaga 1976, 1). A adaptação impressionista de Kontouri dessa tradição é indicativa de sua abordagem ampla dos modelos teatrais japoneses que ela, criativamente, toma emprestado.

A música que acompanha a produção também se baseia em uma mistura de tradições teatrais. Ela foi caracterizada por tonalidades surrealistas. No início da apresentação, um barulho desagradável de arranhão, semelhante ao de unhas em um quadro negro, acompanha a primeira parte de um desenho de uma linha de um círculo vermelho no chão do palco, antecipando os atos sangrentos de Medeia. O círculo se expande gradualmente ao longo da apresentação. A batida de matracas de madeira em momentos chave da produção de 1997 evoca a música teatral japonesa. O uso de matracas $(k i)$ forma uma parte integral de qualquer apresentação de kabuki. Eles são tocados pelo kyōgen sakusha, cujo trabalho é o de fornecer indícios auditivos que direcionam a ação no palco, tanto nos ensaios como na apresentação (Kawatake 2003, 88-93). No kabuki o tempo é fundamental. Kontouri, novamente, aplicou, livremente, este princípio à sua produção de 1997 da Medeia. A utilização de gritos rituais e lamentos, por outro lado, vem das práticas teatrais gregas antigas. ${ }^{29}$

A adaptação criativa de certos elementos dos gêneros teatrais japoneses age como um poderoso símbolo visual e sonoro da alteridade do drama grego antigo. A produção de 1997 buscou quebrar a ilusão de que os espectadores gregos modernos (na verdade, de qualquer grupo de espectadores) podem ter acesso privilegiado ao estado mental do público antigo que assistiu à peça Medeia apresentada no século v a.C. (Grammatas 2006, 113). A releitura de 1997 desafiou deliberadamente a tradição do teatro grego moderno de localizar as releituras dos dramas antigos em ambientes especificamente gregos, a fim de estabelecer uma ligação visual entre a Grécia antiga e a moderna.

${ }^{29}$ Para mais detalhes sobre a prática da lamentação que é ainda encenada em algumas áreas da Grécia moderna como Mani, ver Foley 2001, 152-3. 


\section{A PRODUÇÃO: UMA MEDEIA GREGA MODERNA}

A produção grega moderna de Medeia que discutimos aqui foi apresentada pela primeira vez durante o festival de verão de 1997 (National Theatre of Greece Archive ID621). Ela ficou bastante tempo em cartaz, porque, em seguida, houve uma turnê mundial, por ser um a peça da companhia. Em uma sessão dupla com a Electra de Sófocles (1998), ela teve várias apresentações de gala para celebrar o trabalho do Teatro Nacional da Grécia. ${ }^{30}$ A produção e sua trajetória no exterior demonstram a importância contínua da tradição de encenar a "relação especial" que a Grécia moderna afirma ter com a Grécia antiga. Outro momento teatralmente significativo foi a incorporação do festival em Epidauro, no Festival Hellenico (1998). ${ }^{31}$

Esta produção particular da Medeia desfruta de uma posição central em relação a vários desenvolvimentos chave na vida teatral da Grécia moderna. Ela se tornou um momento marcante na recriação da tragédia antiga. Da mesma forma, celebra a vitória do demótico sobre o katharevousa no palco teatral. Ela foi um exemplo da adoção da estética democrática pelas principais companhias e do emprego que elas fizeram de tais produções como exemplos representativos das realizações culturais no país.

A decisão de envolver Kontouri, uma diretora, é indicativa do desejo de uma abordagem mais inclusiva na recriação do drama antigo. A estética democrática da produção foi confirmada pelo uso da tradução em demótico de Giorgios Chimonas (1936-2000), publicada em 1989. A acessibilidade da tradução dos dramas antigos por Chimonas, que inclui também a Electra de Sófocles, e The Bacchae e Orestes, ambos de Eurípides, levou ao seu uso extensivo no currículo das escolas gregas. Chimonas faz homenagem ao katharevousa, ao manter o sistema de acentuação antigo em suas traduções. Ele pertence a uma geração de intelectuais que foram educados usando essa linguagem artificialmente construída, e suas traduções refletem, assim, as lutas da "Questão da Língua", pelo menos em termos de forma, apesar de seu idioma ser o demótico. Espectadores gregos modernos podiam, portanto, seguir facilmente os monólogos, os diálogos e passagens corais, que formam o $\log o s$ da apresentação. Esse aspecto da produção foi concebido para conduzir o espectador para o mundo da peça.

\footnotetext{
${ }^{30}$ A turnê incluiu paradas na Turquia e França (1997), seguida pela Austrália, por Israel, por Portugal, pelos EUA (1998), por Canadá (1998-1999) e pela Bulgária, pela China e pelo Japão (1999). Informações sobre o tour na forma de programas, jornais, e artigos de revista e resenhas são mantidas em arquivo. Um extrato está disponível digitalmente, mas muito mais pode ser encontrado no dossiê dedicado à produção.

${ }^{31}$ Seu nome completo é The Athens and Epidaurus festival: <http://www.greekfestival.gr>, acesso em 15.02.2011.
} 
Outro elemento de apelo popular nessa produção foi a escolha de uma atriz famosa, neste caso Karyofyllia Karabeti, para o papel de Medeia. Karabeti ganhou notoriedade no seu papel de Maria, na série The Yellow File, exibida na televisão grega em $1991 .^{32}$ A série era baseada no romance homônimo de Michalis Karagatsis (1908-1960), publicado em 1955. ${ }^{33}$ Karabeti atuou como Maria Rousi, uma heroína apaixonada, levada aos extremos por seu amante manipulador, Manos Tasakos. No final da estória, Maria acerta um tiro fatal que mata Manos (Karagatsis 2008, 148-53). Karabeti consolidou sua imagem pública como femme fatale em outro papel na televisão, como Martha em Dyed Red Hair (1992). Essa série é baseada em outro romance, de Kostas Mourselas (1932-?), que se tornou um bestseller após sua publicação, em 1989, apresentando Karabeti com outra oportunidade de atuar como uma mulher apaixonada enveredada nas armadilhas das estruturas da sociedade grega moderna. As adaptações literárias populares eram parte do desenvolvimento da cultura demótica grega moderna. $\mathrm{O}$ público grego moderno pode, assim, associar as heroínas de sangue-quente de Karabeti, encarando dilemas trágicos. A representação de Karabeti de Medeia como uma mulher apaixonada, traída por seu marido fraco e ambicioso, atua sobre as expectativas do público grego moderno, bem como na construção de sua persona.

Esses elementos estéticos da produção foram equilibrados pela severidade da produção, que enfatizou os elementos rituais do drama. O contraste entre aspectos "democráticos"/"inclusivos" da produção, concebidos para atrair os espectadores gregos modernos, e aqueles elementos que ajudam a audiência a manter uma distância crítica do drama eram uma característica marcante. Esse movimento entre atração e repulsão, que, de acordo com Chimonas, é uma parte do apelo característico do drama grego antigo (Chimonas 1989, 9), encontra expressão na produção de Kontouri e redireciona o argumento da autenticidade para outro sentido. O objetivo, agora, se torna o engajamento do público na apresentação, na medida em que, simultaneamente, é reafirmada a importância do ritual e da preservação da distância crítica necessária.

Com esse fim, a produção foi acrescida pelo emprego do estilo de teatro físico [a physical acting], que evoca o modelo japonês para envolver a ação no palco com uma aura de ritual. O agon entre Medeia e Creonte exemplifica esse aspecto da produção. Creonte segura um bastão negro e fica parado no palco na maior parte da cena, enquanto Medeia anda em volta e, de fato,

\footnotetext{
${ }^{32}$ A série foi dirigida por Kostas Koutsomytis e exibida no canal grego Antenna.

${ }^{33}$ Pseudônimo literário de Dimitris Rodopoulos, novelista, crítico e dramaturgo.
} 
segura o bastão quando tenta conseguir mais um dia. Seus movimentos nessa cena e ao longo de toda a produção são precisamente coreografados e envoltos em uma aura ritual. Ao longo da apresentação, Karabeti repete um movimento mais do que qualquer outro, aquele de inclinar o corpo e se dobrar encurvando. Isso funciona como um símbolo visual da dor de dar à luz, apelando para a comunicação física intercultural, para se referir à experiência da dor universalmente compartilhada. Esse gesto também serve para antecipar o infanticídio.

No primeiro agon, com seu antigo marido, Medeia está fisicamente separada de Jasão. Ele aparece pela primeira vez no teto do palco, quando, arrogantemente, se dirige à sua mulher. $\mathrm{O}$ antigo casal, então, se posiciona em lados opostos do palco, enquanto discutem. Como a raiva de Medeia cresce, o coro usa longas faixas brancas como meio de evitar que ela toque em Jasão, o que indica que sua paixão possa levá-la a atacá-lo em frente ao público. O único apoio masculino que Medeia recebe vem de Egeu (Aris Labesopoulos), e a produção indica isso na escolha da roupa branca para o rei de Atenas. Ele também carrega um ramo de oliveira, sinal para indicar, visualmente, sua função na peça como a única possível fonte de apoio e oferta de um santuário que permita à heroína levar a cabo sua vingança. No entanto, mesmo nessa cena, a tensão de Medeia é enfatizada pelo modo como Karabeti circula em torno de Egeu, como ela faz com outros personagens masculinos no drama, demonstrando seu temor deles, bem como seu controle sobre eles e sobre a situação em geral. Medeia é retratada como caça e caçador nessas cenas. Ela alcança seus objetivos pelo poder de suas palavras, por sua peitho.

Os poderes mágicos de Medeia são aludidos sutilmente na cena em que ela oferece o véu dourado e a coroa para seus filhos levarem à princesa. Nessa produção, ela aparece vestida com eles, mostrando sua imunidade a seus próprios pharmaka (uma palavra que aparece várias vezes na tradução). O horror da morte da princesa, quando o véu e a coroa começam a dissolver seu rosto, é descrito graficamente pela mensageira, quando ela dá as notícias à Medeia. Kontouri ecoa, assim, certos aspectos do retrato de Medeia como feiticeira, um elemento forte na história da recepção da heroína trágica. Porém, esse não é um elemento dominante na produção desse drama moderno. Em vez disso, Medeia é apresentada como uma heroína apaixonada, cujo desejo justificável de vingança a conduz, inexoravelmente, ao infanticídio. Kontouri dá peso igual ao retrato da dor maternal de $\mathrm{Me}-$ deia, porque, sem esse aspecto da história, a heroína perderia a simpatia do público. Assim, a produção enfatiza essa dor, mais do que no infanticídio, sendo isso parte da estratégia da diretora para fazer de sua Medeia uma figura tocante, levada a agir por motivos plausíveis. 
É a luta interna de Medeia a respeito de sua decisão de matar as crianças que forma o núcleo emocional da produção de 1997. Esse é um elemento chave na tragédia de Eurípides (Easterling 1977, 177-91). A controvérsia em torno da decisão de Medeia de matar seus filhos e o grau de sua culpabilidade dão à sua história significância e proeminência contínua. É provável que o infanticídio deliberado seja uma das inovações de Eurípides (Knox 1977, 194) e, como tal, levanta a inevitável questão do porquê de o dramaturgo ter escolhido retratar sua heroína desse modo. Autores modernos de teatro respondem de maneira bem diferente a essa complexa questão, mas cada nova produção volta a ela na tentativa de construir sua própria resposta. Kontouri enfatizou os elementos que fariam a decisão de sua Medeia compreensível para o público grego moderno.

Em um estudo recente, Hall demonstrou a relevância do mito no mundo contemporâneo, afirmando que Medeia se encaixa no perfil das mães que cometem filicídio (Hall 2010, 16-17). A vingança contra o marido é o caso mais comum. Mais importante, no entanto, é que Hall aponta para a importância da contextualização de ambos, da tragédia antiga e de sua recepção atual, se quisermos enriquecer nossa compreensão do drama a partir de uma perspectiva interdisciplinar. A produção de 1997 foi montada para fazer a heroína trágica simpática a audiência, apesar de sua decisão de matar as crianças. Para o público grego, essa ação seria normalmente difícil de aceitar, dado o alto valor cultural que é atribuído à família nessa sociedade. $\mathrm{O}$ efeito distanciador que o mito tem permite uma reavaliação desse curso de ação tão chocante como apresentado por Karabeti sob a direção de Kontouri.

Na cena em que a Medeia de Karabeti contempla o infanticídio, e experiência várias e rápidas mudanças no coração, ela vagarosamente rasga um véu branco quando prevê a morte dos filhos amados. Na tradução de

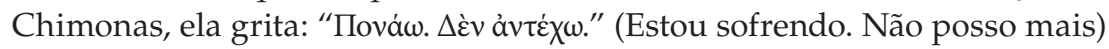

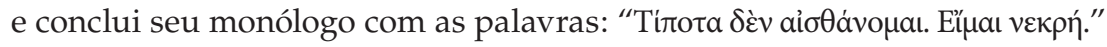

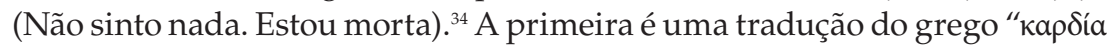
үàp oíxetaı" (meu coração está arruinado), mas a segunda é uma extrapolação do tema do poder de seu "Ovнóc" (raiva/paixão) em sobrepujar seus sentimentos maternais. ${ }^{35} \mathrm{O}$ sentido desses versos é debatido: Medeia está genuinamente arrasada ou existe um elemento de cálculo também envolvido aqui? ${ }^{36}$ Chimonas resolve essa ambiguidade, escolhendo mudar o foco

\footnotetext{
${ }^{34}$ Chimonas $(1989,66-7)$. Todas as traduções do grego moderno são da autora.

${ }^{35}$ Para esse texto, uso a edição de Cambridge de Mastronarde (2002, 1042 e 1079-80, respectivamente). Sobre a controvérsia em torno do fim do discurso de Medeia, ver: n. 1079 (344-45), Mastronarde (2010, 201-2) e também Hall (2010, 20-2) sobre esse tema chave.

${ }^{36}$ Veja a introdução geral de Mastronarde $(2002,21-2)$ e, mais extensivamente, Foley (2001, 244-57).
} 
diretamente para a dor maternal de Medeia. O único modo de ela cometer o infanticídio é congelando suas emoções, tornando-se uma morta em vida. A apresentação de Karabeti joga com esse aspecto da tradução, fazendo-a mais simpática ao público, como uma mãe forçada pelas circunstâncias a cometer o terrível ato.

Nesse momento, na encenação, a maquiagem branca no corpo de Karabeti começava a borrar. A deterioração de sua maquiagem causada pela transpiração amplia o efeito da agonia de Medeia. Ela também levanta algumas questões interessantes em relação à prática de gravar uma apresentação. De um lado, ela preserva a encenação para o futuro, de outro, enfatiza, e, algumas vezes, limita as possibilidades interpretativas. A cena da dor maternal de Medeia é reminiscente de uma da produção de Ninagawa, na qual Medeia puxa uma fita vermelha da boca, referência à sua dor emocional e corporal. A exposição do lamento maternal de Medeia a faz mais simpática ao público e equilibra a fúria de sua paixão. Ambos elementos são necessários a uma produção bem-sucedida de Medeia.

A última cena, “O triunfo de Medeia”, é característica dos valores e da abordagem da produção que Kontouri adotou para sua releitura da tragédia antiga. A fuga triunfal de Medeia na tragédia original produz uma saída visualmente impactante. A escolha do final na produção de 1997 confirmou a importância de uma cortina resistente. Ela retrata Medeia flutuando sobre o palco, olhando para Jasão, que se encontra abaixo. Karabeti aparece em uma grua como um deus ex machina suspenso em um plano acima de Jasão, um poderoso símbolo visual de aniquilação de seu antigo marido e companheiro. A impotência de Jasão é enfatizada quando ele cai de joelhos (literal e metaforicamente). No momento em que Medeia o nega acesso aos corpos dos filhos, ele colapsa totalmente e bate no chão em uma queda que faz um ruído seco. Depois de uma apresentação emocionalmente carregada, Kara-

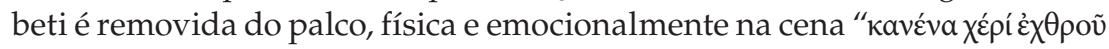

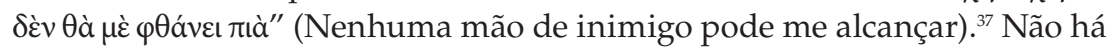
carruagem de dragão, mas sua frieza evoca o distanciamento de uma divindade cruel. Ela fica suspensa no texto e seu longo vestido vermelho cria a impressão de um voo.

O discurso de Karabeti na tradução demótica de Chimonas das palavras de Medeia nas cenas finais dessa releitura da tragédia de Eurí-

${ }^{37}$ Chimonas 1989, 77. Cf. 1322. O tradutor novamente modificou um verso que no texto antigo se refere diretamente à carruagem de Hélios. Medeia diz que este é o meio pelo qual ela é protegida das mãos dos que querem prejudicá-la. Ao tornar esse trecho uma parte independente, que segue após a referência que Medeia faz à carruagem, Chimonas enfatiza a afirmação de Medeia. Ele também o torna um tipo de pronunciamento mais geral. A Medeia de Chimonas está convencida de sua invulnerabilidade nessa cena final. 
pides ilustra o compromisso da produção de fazer da linguagem um dos aspectos "democráticos"/ "inclusivos" da encenação. Nessa cena altamente carregada, a atriz popular, falando em grego demótico, abre uma linha de comunicação direta com o público, permitindo-lhes o acesso à mente dessa Medeia grega moderna. Sua resposta fria à invectiva de Jasão revela sua satisfação profunda - ela conseguiu nocauteá-lo.

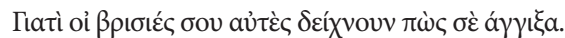

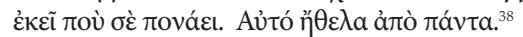

Porque suas profanidades revelam que eu toquei você onde dói. Isto é o que eu sempre quis.

E depois:

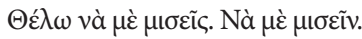

Eu quero que você me odeie. Me odeie. ${ }^{39}$

A tradução concisa e às vezes bastante livre de Chimonas expressa júbilo frio de Medeia ao derrotar seu oponente. Para ela, a reação de Jasão, sua perda de controle e seu recurso a invectivas justifica sua decisão de matar os filhos: esse é o melhor modo de retribuir o mal tratamento que ele deu a ela. Tanto a tradução como a apresentação de Karabeti reforçam a impressão de que Medeia divorciou-se do que previamente mais importava para ela, seu casamento e seus filhos. Seu triunfo permite a ela se distanciar emocionalmente de seu crime. Karabeti, na direção de Kontouri, consegue a simpatia de sua audiência, ao usar o idioma demótico como meio de conectar com os espectadores no nível da linguagem. De fato, Kontouri e Karabeti fizeram o público manter uma cumplicidade com Medeia, na versão da tragédia de Eurípides.

${ }^{38}$ Chimonas 1989, 79. Cf. 1360. É interessante que Chimonas escolheu não usar a palavra

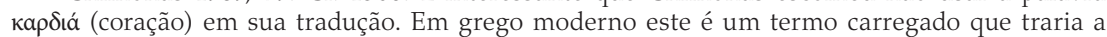
imagem de uma ligação estreita entre Jasão e seus filhos, que o tradutor parece, não sem curso, evitar. Sua simpatia, como a da produção de 1997, parece estar com Medeia.

${ }^{39}$ Chimonas 1989, 80. Cf. 1374. Chimonas traduziu os versos 1361-77 bastante livremente. Durante a esticomitia entre Jasão e Medeia, Chimonas faz sua heroína alongar a palavra grega antiga $\sigma \tau \vartheta \gamma \varepsilon ́ \omega$ (ódio). Ao alongar o termo e ao fazer sua Medeia repeti-la enfaticamente, ele a retrata como uma mulher que pede para que seu antigo marido a odeie - esta é uma parte essencial da vingança dela sobre ele, a prova de que ela o machucou profundamente. 


\section{CONCLUSÃO}

O sucesso excepcional da produção de Medeia de 1997 no Teatro Nacional, tanto no país como no exterior, principalmente no período em que grandes mudanças estavam sendo implementadas na organização do Festival Helênico (anteriormente Festival de Atenas), marcaram essa produção como uma releitura digna de nota. Ela serviu como um importante estudo de caso para o novo momento do palco grego moderno desde a adoção oficial do demótico.

A combinação de estilos, tradições e práticas nas quais esta produção se desenvolve deliberadamente a divorcia de qualquer tempo e espaço determinados. A natureza sintética dessa releitura de Medeia evoca muitos modelos, mas não se apoia em nenhum em particular. A diretora planejou a encenação para uma plateia de gregos. Certos elementos da produção funcionam menos quando a encenação é no exterior, como no caso da performances que ocorreram no Japão. Ainda assim, ela se mantém consistente pela incrível atuação de Karabeti como Medeia. De acordo com Gramma-

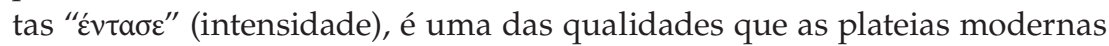
acham mais impressionantes $(2006,57)$, e Karabeti certamente atuou com tal intensidade.

A escolha do demótico e de uma atriz popular para Medeia objetivou o engajamento do público moderno, enquanto o uso de elementos teatrais estrangeiros objetivou a criação de um distanciamento necessário que permitiria ao público se envolver com a peça antiga criticamente. Kontouri deliberadamente escolheu se afastar da tradição teatral grega moderna e de sua busca por autenticidade. Ela se alinhou com a nova onda de diretores que se rebelaram contra essa tradição estabelecida e escolheu experimentar novas abordagens que abriram o palco do teatro grego moderno a novas influências e modelos. É essa combinação que faz a Medeia de Kontouri “democrática" no melhor sentido do termo. A acessibilidade ao logos da produção e seu desejo de se engajar criativamente com múltiplos modelos, em vez de se confinar à camisa de força da tradição, contribuíram para a sua popularidade com os espectadores contemporâneos de teatro.

A produção da Medeia de Kontouri de 1997 se tornou um marco na prática teatral de retomar o drama antigo na Grécia moderna. Ela assinala o desejo de jovens diretores de colocar essas recriações em um novo caminho em que, ao mesmo tempo, se inspira na e desafia a tradição teatral grega moderna na encenação dessas peças. A produção é também um paradigma para o processo de democratização em curso. O idioma demótico permitiu aos espectadores gregos modernos ter um acesso direto ao logos do drama, 
fazendo da linguagem o aspecto mais familiar da representação. $\mathrm{O}$ triunfo de Medeia, que trouxe a produção para uma conclusão tão exitosa, tornou-se, assim, emblemático do triunfo do demótico sobre a katharevousa. A Medeia de Konturi anunciou uma nova era na retomada da tragédia grega antiga no palco grego moderno, na qual as produções são moldadas não apenas por uma perspectiva local, mas são também sensíveis e atentas a tendências no teatro mundial..$^{40}$

\section{REFERÊNCIAS}

Alexiou, M. 1982. “Diglossia in Greece." In Standard Languages, Spoken and Written, ed. W. Haas, 156-92. Manchester: Manchester University Press.

Archive for the Performance of Greek and Roman Drama. University of Oxford. $<$ http:://www.apgrd.ox.ac.uk/database>.

Athens Festival; Hellenic Festival. <http://www.greekfestival.gr>

Attis. Companhia de teatro grega fundada por Theodoros Terzopoulos e especializada em recriações do drama grego antigo. <http://www.attistheatre.com>

Beaton, R. 1999. An Introduction to Modern Greek Literature. 2. ed. Oxford: Oxford University Press.

Carabott, P. 1993. "Politics, Orthodoxy and the Language Question in Greece: The Gospel Riots of November 1901." Journal of Mediterranean Studies 3(1): 117-38. Malta: The Mediterranean Institute, University of Malta.

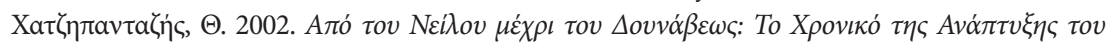

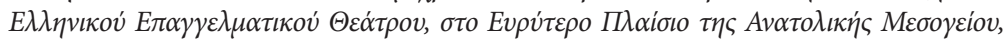

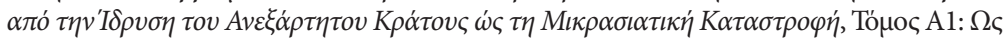

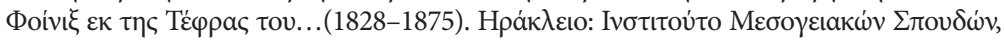

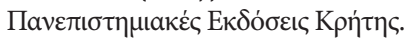

Chatzipadazis, T. 2002. From the Nile to the Danube: a Chronicle of the Development of Greek Professional Theatre in the Context of the Eastern Mediterranean, from the Foundation of the Independent State till the Asia Minor Disaster. Iraklion: Institute for Mediterranean Studies at the University of Crete.

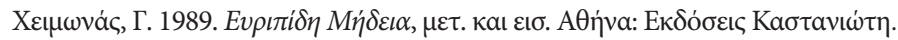

\footnotetext{
${ }^{40}$ Meus sinceros agradecimentos a Lorna Hardwick e a Stephen Harrison, pela valorosa assistência editorial. Agradeço, também, à Carol Gillespie, por seu grande esforço, que ajudou a fazer do congresso Classics in the Modern World: A "Democratic Turn"? um evento tão agradável. Também devo à Gonda Van Steen a gratidão pela ajuda e pelos comentários inspiradores. Gostaria, ainda, de expressar meus agradecimentos sinceros à equipe do arquivo do National Theatre of Greece e do Archive for the Performance of Ancient Greek and Roman Drama em Oxford, pelo acesso a fontes primárias de grande valor. Eu também agradeço a ajuda de George Sampatakakis do departamento de estudos teatrais (University of Patras) na discussão que faço da obra de Theodoros Terzopoulos. Em relação à transliteração do grego moderno, substituí " $\eta$ " por "i", por exemplo, dimotiki, a menos que outra pronúncia tenha sido estabelecida.
} 
Chimonas, G. 1989. Euripides' Medea, trans. into modern Greek with intro. Athens: Kastanioti.

Corti, L. 1998. The Myth of Medea and the Murder of Children. London: Greenwood Press.

Easterling, P. 1977. "The Infanticide in Euripides' Medea." In Greek Tragedy, ed. T. F. Gould and C. J. Herinton, 177-91. Cambridge: Cambridge University Press. (Yale Classical Studies 25.)

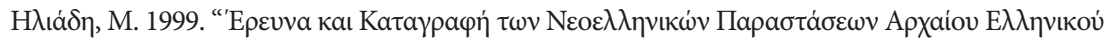

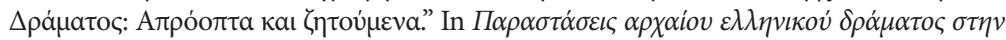

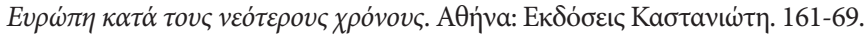

Eliade, M. 1999. "Researching and Recording Modern Greek Productions of Ancient Greek Drama. The Unpredictable and the Desirable." In Productions of Ancient Greek Drama in Europe During Modern Times, ed. P. Mauromoustakos, 161-9. Athens: Kastanioti.

Fletcher, R. 1984. Kostes Palamas: A Great Modern Greek Poet - His Life, his Work and his Struggle for Demoticism. Athens: Idryma Kosti Palama.

Foley, H. P. 2001. Female Acts in Greek Tragedy. Princeton: Princeton University Press.

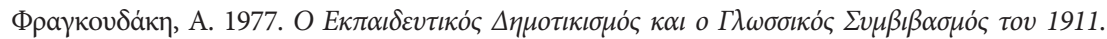

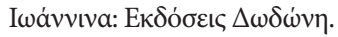

Fragoudaki, A. 1977. Dimotiki in Pedagogy and the Linguistic Compromise of 1911. Ioannina: Dodoni Publications.

Fragoudaki, A. 1992. "Diglossia and the Language Situation in Greece." Language in Society 21: 365-81. Cambridge: Cambridge University Press.

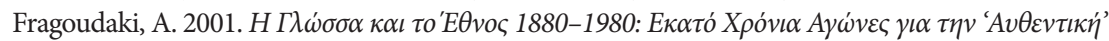

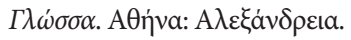

Fragoudaki, A. 2001. Language and the Nation 1880-1980: The One Hundred Year Struggle for an 'authentic' Greek language. Athens: Alexandria.

Georgakopoulou, A.; Silk, M., ed. 2009 Standard Languages and Language Standards: Greek, Past and Present. Farnham: Ashgate.

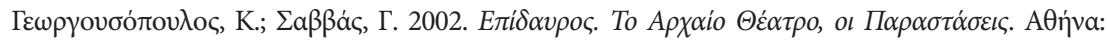

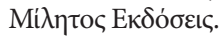

Georgousopoulos, K.; Savas, G. 2002. Epidaurus. The Ancient Theatre, the Performances. Athens: Militos Publishing.

Goutsos, D. 2009. "Competing ideologies and Post-Diglossia Greek: Analysing the Discourse of Contemporary 'Myth-Breakers'." In Standard Languages and Language Standards: Greek, Past and Present, edited by A. Georgakopoulou and M. Silk, 321-39. Farnham: Ashgate.

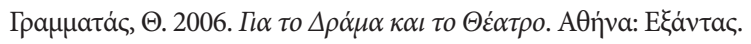

Grammatas, Th. 2006. On Drama and Theatre. Athens: Exandas.

Hall, E. 2010. "Medea and the Mind of the Murderer." In Unbinding Medea: Interdisciplinary Approaches to a Classical Myth from Antiquity to the 21 $1^{\text {st }}$ Century, ed. $\mathrm{H}$. Bartel and A. Simon, 16-24. London: Legenda.

Hall, E.; Macintosh, F.; Taplin, O., ed. 2000. Medea in Performance, 1500-2000. Oxford: Legenda.

Hardwick, L. 2000. Translating Words, Translating Cultures. London: Duckworth.

Hardwick, L.; Stray, C. 2008. "Introduction: Making Connections." In A Companion to Classical Receptions, 1-9. Oxford: Blackwell. 
Hironaga, S. 1976. The Bunraku Handbook: A Comprehensive Guide to Japan's Unique Puppet Theatre with Synopses of All Popular Plays. Tokyo: Maison des Arts, Inc.

Iles Johnston, S. 1997. "Introduction" to Medea. Essays on Medea in Myth, Literature, Philosophy, and Art, ed. J. J. Clauss and S. Iles Johnston, 1-17. Princeton: Princeton University Press.

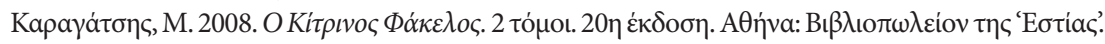
Karagatsis, M. 2008. The Yellow File. 2 vols. 20. ed. Athens: Estias Bookshop.

Kawatake, T. 2003. Kabuki: Baroque Fusion of the Arts. Trans. F. and J. Connell Hoff. Tokyo: The International House of Japan, Inc.

Knox, B. M. W. 1977. "The Medea of Euripides.” In Greek Tragedy, ed. T. F. Gould and C. J. Herinton , 193-225. Yale Classical Studies vol. 25. Cambridge: Cambridge University Press.

Leiter, S. L., ed. 2002. A Kabuki Reader: History and Performance. New York: M. E. Sharpe, Inc.

Llewellyn-Jones, L. 2005. "Body Language and the Female Role Player in Greek Tragedy and Japanese Kabuki Theatre." In Body Language in the Greek and Roman Worlds, ed. D. Cairns, 73-105. Swansea: The Classical Press of Wales.

Mackridge, P. 2009. Language and National Identity in Greece 1766-1976. Oxford: Oxford University Press. (Rev. 2010)

Mastronarde, D. J., ed. 2002. Euripides' Medea. Cambridge: Cambridge University Press.

Mastronarde, D. J. 2010. The Art of Euripides: Dramatic Technique and Social Context. Cambridge: Cambridge University Press.

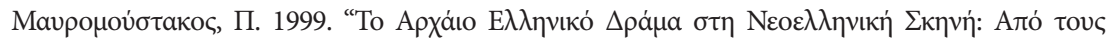

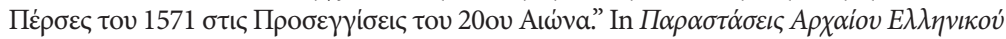

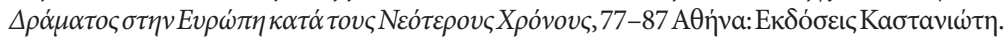

Mauromoustakos, P. 1999. "Ancient Greek Drama on the Modern Greek Stage: From the Persians of 1571 to Twentieth-Century Approaches." In Productions of Ancient Greek Drama in Europe during Modern Times, 77-87 Athens: Kastaniotis Publishing.

Michelakis, P. 2001. "The Past as a Foreign Country? Greek Tragedy, Cinema and the Politics of Space." In Homer, Tragedy and Beyond. Essays in Honour of P. E. Easterling, ed. F. Budelmann and P. Michelakis. London: SPHS.

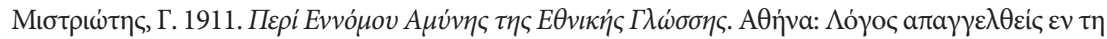

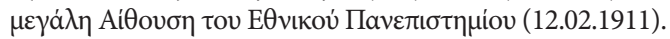

Mistriotis, G. 1911. The Defence of the National Language in Law. Athens: Speech delivered at Athens University (12.02.1911).

Moschonas, S. 2009. "Language Issues' after the 'Language Question': On the Modern Standards of Standard Modern Greek." In Standard Languages and Language Standards: Greek, Past and Present, edited by A. Georgakopoulou and M. Silk, 293-320 Farnham: Ashgate.

National Theatre of Greece . <http://www.nt-archive.gr>

Raddatz, F. M., ed. 2006. Journey with Dionysos. The Theatre of Theodoros Terzopoulos. Berlin: Theater der Zeit.

Rubino, M. 2000. Medea Contemporanea: Lars von Trier, Christa Wolf, Scrittori Balcanici. Genova: Darficlet.

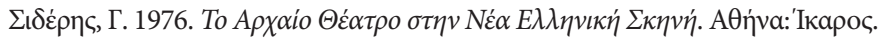


Sideres, G. 1976. The Ancient Theatre on the Modern Greek Stage, 1817-1932. Athens: Ikaros.

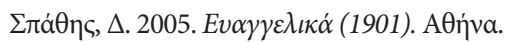

Spathes, D. 2005. Evangelika (1901) - Oresteiaka (1903): Modernizing Pressures and Society's Acts of Resistance. Athens: Society for the Promotion of Hellenic Culture and General Pedagogy.

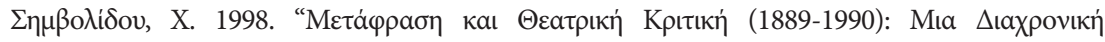

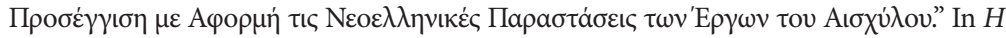

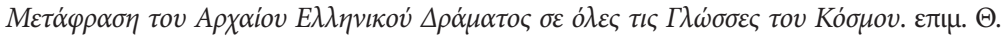

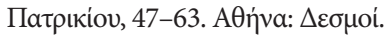

Symvoulidou, Ch. 1998. "Translation and Theatre Criticism (1889-1990): A Diachronic Approach Based on the Modern Greek Productions of the Plays of Aeschylus." In The Translation of Ancient Greek Drama in all the Languages of the World, ed. H. Patrikiou, 47-63. Athens: Desmoi.

Van Steen, G. 2000. Venom in Verse: Aristophanes in Modern Greece. Princeton, N.J.: Princeton University Press.

Van Steen, G. 2008. "You Unleash the Tempest of Tragedy'. The 1903 Athenian Production of Aeschylus' Oresteia." In A Companion to Classical Receptions, ed. L. Hardwick and C. Stray, 360-72. Oxford: Blackwell.

Van Steen, G. 2010. Liberating Hellenism from the Ottoman Empire. Comte de Marcellus and the Last of the Classics. New York: Palgrave MacMillan.

Varopoulou, H.; McDonald, M.; Suzuki, T. 2001. Theodoros Terzopoulos and the Attis Theatre. History, Methodology and Comments. Athens: Agra.

Walton, J. M. 2009. Euripides our Contemporary. London: Methuen Drama.

\section{$*$}

Title. Demotic power to the people: the triumph of dimotiki, the triumph of Medea

Abstract. This paper examines a modern production of Euripides' Medea (431 b.C.), staged in the last years of the 20th century, in the Greek National Theatre, directed by Niketi Contour. Significantly connected to a specific political atmosphere, which, I believe, was created by the Greek official resolution concerning the infamous "Language Issue", it offers a singular point of view to consider Euripides' play in a contemporary perspective, as well as the Greek drama modern reception as a whole.

Keywords. Medea; Euripides; reception studies. 